\title{
PHA-Induced Peripheral Blood Cytogenetics and Molecular Analysis: a Valid Diagnostic and Follow-up Modality for Acute Promyelocytic Leukemia Patients Treated with ATRA and/or Arsenic Tri-oxide
}

\author{
Shahid M Baba ${ }^{1}$, Niyaz A Azad $^{1}$,Zaffar A Shah ${ }^{1 *}$, Dil Afroze $^{1}$, Arshad A Pandith ${ }^{2}$, \\ Aleem Jan ${ }^{3}$, Sheikh A Aziz ${ }^{4}$, Fayaz A Dar ${ }^{2}$
}

\begin{abstract}
Background: Acute promyelocytic leukemia (APML) is characterized by the reciprocal translocation $t(15 ; 17)$ (q22;q12) resulting in the PML-RAR $\alpha$ fusion gene. A dual diagnostic and follow up approach was applied including cytogenetic demonstration of the $t(15 ; 17)$ translocation and detection of PML-RAR $\alpha$ chimeric transcripts by molecular means. Purpose: Conventional cytogenetics involving bone marrow is beset with high probability of poor metaphase index and was substituted with phytohemagglutinin (PHA)-induced peripheral blood culture based cytogenetic analysis as a diagnostic \& follow up modality in APML patients of Kashmir (North India). Both qualitative (RT-PCR) and quantitative (Q-PCR) tests were simultaneously carried out to authenticate the modified cytogenetics. Materials and Methods: Patient samples were subjected to the said techniques to establish their baseline as well as follow-up status. Results: Initial cytogenetics revealed 30 patients $(81 \%)$ positive for $t(15 ; 17)$ whereas $7(19 \%)$ had either cryptic translocation or were negative for $t(15 ; 17)$. Two cases had chromosome $16 q$ deletion and no hallmark translocation $t(15 ; 17)$. Q-PCR status for PML-RAR $\alpha$ was found to be positive for all patients. All the APML patients were reassessed at the end of consolidation phase and during maintenance phase of chemotherapy where 6 patients had molecular relapse, wherein 4 also demonstrated cytogenetic relapse. Conclusions: It was found that PHA-induced peripheral blood cytogenetics along with molecular analysis could prove a reliable modality in the diagnosis and assessment of follow up response of APML patients.
\end{abstract}

Keywords: APML - cytogenetic response - ATRA - arsenic tri-oxide - peripheral blood - karyotyping

Asian Pac J Cancer Prev, 17 (4), 1999-2006

\section{Introduction}

Acute promyelocytic leukemia (APML) is a distinct subtype of acute myeloid leukemia. Morphologically, it is identified as AML-M3 by the French-AmericanBritish (FAB) classification. Cytogenetically, APML is characterized by a balanced reciprocal translocation between chromosomes 15 and 17, which results in the fusion between the promyelocytic leukemia (PML)gene and retinoic acid receptor (RAR).Variant chromosomal translocations e.g., $\mathrm{t}(11 ; 17), \mathrm{t}(5 ; 17)$ can be detected in no more than $5 \%$ of APML patients.

The real incidence of APML is not known. The percentage of APML could be higher in children than in adults (So et al., 2011). The incidence is somewhat around $5 \%$ to $13 \%$ reported by many large clinical trials and single institutions in the US. Also of note, this incidence is similar to Latin American background patients (Douer et al., 2003).

The genetic hallmark of APML is the balanced reciprocal translocation $\mathrm{t}(15 ; 17)(\mathrm{q} 22 ; \mathrm{q} 21-12)$ leading to the fusion of the promyelocytic (PML) gene on chromosome 15 and the retinoic acid receptor- $\alpha(\operatorname{RAR} \alpha)$ gene on chromosome 17. Depending on the location of breakpoints within the PML site, the PML/RAR $\alpha$ transcript subtypes bcr1, bcr2 and bcr3 may be formed. Of these, bcr1 and bcr2 are of similar size and together referred to as long (L) isoform, bcr2 as vari-able (V) and bcr3 as short (S) isoform. The PML/RAR $\alpha$ fusion is detectable by fluorescence in situ hybridization (FISH) or reverse-transcriptase polymerase chain reaction (RT-PCR) in $>95 \%$ of morphologically defined APMLs, while in the remaining cases several variant rarerangements have been described that constantly involve RAR $\alpha$ and partner genes other than PML (Grimwade, 1999).

RAR $\alpha$ is a member of the RA nuclear receptor

${ }^{1}$ Department of Immunology and Molecular Medicine, ${ }^{2}$ Advanced Centre for Human Genetics, ${ }^{3}$ Department of Clinical Hematology, ${ }^{4}$ Department of Medical Oncology, Sher-I-Kashmir Institute of Medical Sciences, Srinagar, J and K, India *For correspondence: bshahid007@gmail.com,zaffaramin@gmail.com 


\section{Shahid M Baba et al}

family that acts as ligand-inducible transcription factor by binding to specific response elements (RARE) at the promoter region of target genes. In the absence of ligand, $\mathrm{RAR} \alpha$ forms heterodimers with the retinoid $\mathrm{X}$ receptor (RXR) and recruits a co-repressor complex containing histone deacetylase (HDAC) activities that induces chromatin condensation and transcriptional repression. Physiological concentrations of RA (it as $1 \times 10$ raised to power $9 \mathrm{M}$ ) are able to release the nuclear co-repressors complex from the RAR-RXR and recruit co-activators with histone acetyltransferase activities (HAT). This results in hyperacetylation of histones at RARE sites, chromatin remodeling and transcriptional activation of RAR $\alpha$-target genes (Dilworth and Chambon, 2000; Glass and Rosen-feld, 2000).

PML belongs to a family of proteins containing a distinctive $\mathrm{C} 3 \mathrm{HC} 4$ zinc-binding domain referred to as RING finger. Like other members of this family, including BRCA1, PML has been implicated in tumor suppression and control of genomic stability (Zhong S, et al., 2000). In the nucleus, PML is detected in multiprotein complexes termed PML nuclear bodies, where it co-localizes with other proteins such as p53, pRb, Daxx, and CBP (Jensen K, et al., 2001). As a consequence of the PML/ RAR $\alpha$ fusion, in APML cells, PML is disrupted and the protein is de-localized into microspeckled nuclear particles. This variation in subcellular distribution of PML in APMLs bearing the PML/RAR $\alpha$ rearrangement is clinically relevant as it allows rapid diagnosis through immunostaining techniques.

The PML-RAR $\alpha$ protein functions as an aberrant retinoid receptor with altered DNA-binding properties as compared to wild type $\operatorname{RAR} \alpha$, and it acts as repressor of RA signaling. PML-RAR $\alpha$ can heterodimerize with the RXR, with PML and with another PML-RAR $\alpha$ chimeric protein forming a homodimer. Distinct from wild-type RAR $\alpha$, the repression induced by un-liganded PML-RAR $\alpha$ is releasable only by pharmacological doses of ATRA (10-6 M). This is explained by the fact that compared to wild-type RAR $\alpha$, the PML-RAR $\alpha$ hybrid binds the histone-deacetylase (HDAC)-recruiting co-repressor complex with higher affinity (Pandolfi PP, 2001). In addition to recruiting HDAC activity, PML/ RAR $\alpha$ is also able to bind the DNA methylating enzymes Dnmt1 and Dnmt3a, leading to the methylation of RA target promoters in APML blasts (Di Croce L, et al., 2009; Villa R, et al., 2006). In summary, PML/RAR $\alpha$ acts through various mechanisms as a constitutive and potent transcriptional repressor of RAR $\alpha$-target genes (Carbone R, et al., 2006).

AML's a rare among the considerably incident AML leukemia's and ranks as the fifth among commonly occurring cancers in the Kashmir valley (North India) (Pandith and Siddiqi, 2012). We for the first time aimed at evaluating the efficacy of the peripheral blood cytogenetic technique along with molecular analysis in detecting the disease and monitoring the response in APML patients treated with conventional chemotherapy. Base line peripheral blood cytogenetics along with qualitative PCR was performed to look for the type of the transcript followed by real time PCR quantification of the transcript involved.

\section{Materials and Methods}

We analyzed the course of all newly diagnosed and relapsed patients with APML treated consecutively on protocols (ICAPL-2006 and $\mathrm{AS}_{2} \mathrm{O}_{3}$ ) in the department of Clinical Hematology and Medical Oncology at Sher-iKashmir Institute of Medical Sciences, (SKIMS) JandK (North India) and included in the study after a thorough approval from the 'Institute Ethics Committee' (IEC) of SKIMS and subjected to prospective evaluation of their response to conventional chemotherapy(ICAPL-2006 and $\mathrm{AS}_{2} \mathrm{O}_{3}$ ) at the Department of Immunology and Molecular Medicine, SKIMS from 2013 to 2015. All patients had the baseline bone marrow analysis done and were accordingly categorized against the morphologic criteria for the diagnosis of APML [AML-M3] or M3-variant) according to the French-American-British classification system (Bennett JM, et al., 1985). The diagnosis was confirmed by presence of $t(15: 17)$ on peripheral blood cytogenetic studies as well as detection of PML-RAR $\alpha$ translocation by RT-PCR and Q-PCR.

Heparinized peripheral blood for cytogenetics and EDTA blood samples for RT-PCR and Q-PCR were collected after informed consent, from 37 newly diagnosed and relapsed patient. Median age of the patients was 31 years (range 06 to 92 years). We examined samples before patients began treatment, after they achieved clinical complete remission by standard criteria, and periodically thereafter.

\section{Cytogenetic analysis}

Chromosomal analysis of the patients was done at baseline and different stages of treatment as per the ICAPL-2006 and $\mathrm{AS}_{2} \mathrm{O}_{3}$ protocol. Cytogenetic analysis was carried out as per the technique followed in our previous work by Azad et.al (Niyaz A Azad, et al., 2015), wherein 40ul of PHA (Gibco) was added to every $5 \mathrm{ml}$ of RPMI-1640 culture media (Cell Clone) containing 10\% fetal calf serum (Gibco) before adding about $0.5 \mathrm{ml}$ of peripheral blood to it. In addition, a simultaneous PHAfree culture corresponding to each sample was also carried out for comparative purpose. Cultures were incubated for 48-72 hours followed by further 1 hour incubation after adding $50 \mathrm{ul}$ of Colchicine (Loba Chemie- $1 \mathrm{mg} / 10$ $\mathrm{ml})$ and $100 \mathrm{ul}$ of Ethidium bromide $(1 \mathrm{mg} / 10 \mathrm{ml})$ to each vial. Cultures were subsequently put to hypotonic shock with $0.075 \mathrm{M}$ potassium chloride and then fixed in Carnoy's fixative [methanol-acetic acid (3:1)]. Slides were prepared and GTG banding was performed as described by Seabright (Seabrigth M, 1971) Computerized work station- 'Cytovision 3.93' was used to identify and arrange chromosomes as per the International System for Human Cytogenetic Nomenclature (ISCN) (Mitelman F, 1995). At least 20 karyotypes were prepared and analyzed for each sample.

\section{RNA Extraction}

Total RNA from Ficoll-Hypaque separated mononuclear cells from $5-7 \mathrm{ml}$ of peripheral blood was extracted using Trizol (Amresco). The extracted RNA 
was checked for purity and integrity by DEPC-treated agarose gel electrophoresis. Concentration of RNA was measured spectrophotometrically and the ratio of optical density at 260 and $280 \mathrm{~nm}$ checked. A ratio of 1.80 to 2.00 was accepted as good quality RNA.

\section{cDNA Synthesis}

The reverse transcriptase reaction was performed using the Maxima cDNA synthesis kit (Thermo Scientific) containing Enzyme Mix (M-MuLV RT Enzyme and Ribolock Rnase Inhibitor), 5x Reaction Mix (reaction buffer, dNTP's, oligo(dt) 18 and random hexamer primers and Nuclease free water).

Two micrograms of total cellular RNA was reverse transcribed to cDNA by an incubation of 10 minutes at $25^{\circ} \mathrm{C}, 15$ minutes at $500 \mathrm{C}$, and 5 minutes at $85^{\circ} \mathrm{C}$ in a total volume of 20ul that contained 4ul of 5X Reaction Mix, 2ul of Maxima Enzyme Mix and 12ul of nuclease free water.

\section{RT-PCR (Qualitative)}

The amplification method as described by (van Dongen et al., 1999) was followed for qualitative RTPCR studies. Multiplex PCR reaction was carried out in a $25 \mathrm{ul}$ reac-tion volume using reverse and forward primers sets for bcr1, bcr2 and bcr3 transcripts. PML-A1 5'-CAGTGTACGCCTTCTCCATCA-3', PML-A2 5' - CTGCTGGAGGCTGTGGAC-3', RARA-B 5'-GCTTGTAGATGCGGGGTAGA-3' and one self designed primer PML-RP 5'-CTGACTGTACCACAGCCATAGG-3'. Reaction times consisted of an initial denaturation of $94^{\circ} \mathrm{C}$ for 5 minutes, annealing at $54^{\circ} \mathrm{C}$ for $30 \mathrm{secs}$, and elongation at $72^{\circ} \mathrm{C}$ for 7 minutes, followed by 35 additional cycles (30 secs at 94 as centigrade, $30 \mathrm{secs}$ at $54^{\circ} \mathrm{C}$, and $30 \mathrm{secs}$ at $72^{\circ} \mathrm{C}$ ). 6 -8ul of the PCR product was size-fractionated by electrophoresis in a $2 \%$ agarose gel stained with ethidium bromide and visualized under a UV transilluminator (Flourchem, HD2-Cell Biosciences) at $365 \mathrm{~nm}$.

In case of PML/RAR $\alpha$, due to alternative splicing of the breakpoint cluster regions (BCR) on PML locus of chromosome $15, \mathrm{PCR}$ products of various sizes ranging from 345 to 381 bp were found with RARA-B primer which is found to be a "universal primer" for all the three forms of translocations seen in APML (short isoform: intron 3-bcr 3; long variant isoform: exon 6-BCR 2; and long isoform: intron 6-BCR 1). A single product of either 381 or 345 bp was observed with PML-A1 primer that corresponded to the translocation breakpoints intron 6-BCR 1 or exon 6-Bcr2 and 376 bp products was observed with PML-A2 primer correspond-ing to BCR 3 whose breakpoint is located in intron 3. Primers PML-A2, RARA-B and self de-signed PML-RP primer set displayed an additional PCR product of $450 \mathrm{bp}$ which served as an internal control and ensured good quality of cDNA used. Accordingly, the results of PCR for PML/RAR $\alpha$ were interpreted as long (l), long variant (v) isoform or short (s) isoform.

\section{Q-PCR (Quantitative)}

Extracted RNA was normalized to the concentration of approximately 500ng and subjected to the integrated
c-DNA synthesis and real-time quantification by using Taqman probe based PML-RAR $\alpha$ transcripts (bcr1 and bcr3) quantitation kit (Geno-Sen's Genome Diagnostics Pvt. Ltd.) on the Agilent Stratagene Mx-3000-P RealtimePCR platform.

\section{Results}

The APML patients included 24 males $(64.8 \%)$ and 13 females $(35.1 \%)$ ranging from age 6 years to 95 years. 23 patients $(62.1 \%)$ belonged to age group $<30$ yrs and the rest of the 14 patients $(37.8 \%)$ were above $30 \mathrm{yrs}$ of age. Of the 37 patients analyzed 10 patients $(27.0 \%)$ belonged to urban area and the remaining 27 patients $(72.9 \%)$ to rural areas (Table 1).

Patients were risk stratified into low risk, high risk and intermediate risk on the basis of TLC and platelet counts at presentation. 9 of the $37(24.3 \%)$ patients presented with leucocytosis $\left(>10 \times 10^{9} / \mathrm{L}\right)$ and high platelet counts $\left(\geq 40 \times 10^{9} \mathrm{cumm}\right)$, whereas the remaining 28 patients $(75.6 \%)$ had leucopenia $\left(\leq 10 \times 10^{9} / \mathrm{L}\right)$ with low platelet counts $\left(\leq 40 \times 10^{9} /\right.$ cumm) (Table 1$)$.

Bone marrow examination of the patients revealed 07 patients $(18.9 \%)$ with less than $60 \%$ promyelocytes and

Table 1. Clinico-Pathological Parameters of APML Patients and their Cytogenetic and Molecular Profile

\begin{tabular}{|c|c|c|c|}
\hline \multicolumn{2}{|c|}{ Particulars } & \multirow{2}{*}{$\frac{\text { Number }}{24}$} & \multirow{2}{*}{$\begin{array}{c}\text { Percentage } \\
\%\end{array}$} \\
\hline Cond & Male & & \\
\hline 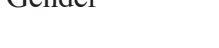 & Female & 13 & 35.1 \\
\hline \multirow{2}{*}{ Age } & $\leq 30$ & 23 & 62.1 \\
\hline & $\geq 30$ & 14 & 37.8 \\
\hline \multirow{2}{*}{ Dwelling } & Urban & 10 & 27 \\
\hline & Rural & 27 & 72.9 \\
\hline \multirow{2}{*}{ Expired } & Male & 5 & 13.5 \\
\hline & Female & 3 & 8.1 \\
\hline \multirow{2}{*}{$\begin{array}{l}\text { TLC } \\
\text { (Baseline) }\end{array}$} & $>10 \times 10^{9} / \mathrm{L}$ & 9 & 24.3 \\
\hline & $<10 \times 10^{9} / \mathrm{L}$ & 28 & 75.6 \\
\hline \multirow{2}{*}{ Platelets } & $>40 \times 10^{9} /$ cum & 28 & 75.6 \\
\hline & $\geq 40 \times 10^{9} / \mathrm{cum}$ & 9 & 24.3 \\
\hline \multirow{2}{*}{ Promyelocytes } & $<60 \%$ & 7 & 18.9 \\
\hline & $\geq 60 \%$ & 30 & 81 \\
\hline \multirow{2}{*}{$\begin{array}{l}\text { q-PCR value } \\
\text { (Baseline) }\end{array}$} & $\geq 60 \%$ & 13 & 35.1 \\
\hline & $<60 \%$ & 21 & 56.7 \\
\hline \multirow{2}{*}{$\begin{array}{l}\text { Karyotyping } \\
\text { (Baseline) }\end{array}$} & $\begin{array}{l}\text { PML-RAR } \alpha \\
\text { Positive }\end{array}$ & 30 & 81 \\
\hline & $\begin{array}{l}\text { PML-RAR } \alpha \\
\text { Negative }\end{array}$ & 7 & 19 \\
\hline \multirow{3}{*}{$\begin{array}{l}\text { Transcript type } \\
\text { Qualitative PCR }\end{array}$} & Bcr1 & 22 & 59.4 \\
\hline & Bcr2 & 3 & 8.1 \\
\hline & Bcr3 & 12 & 32.4 \\
\hline \multirow[b]{2}{*}{ Therapy } & & 27 & 72.9 \\
\hline & $\begin{array}{l}\text { Arsenic } \\
\left(\mathrm{AS}_{2} \mathrm{O}_{3}\right)\end{array}$ & 10 & 27.1 \\
\hline
\end{tabular}


Table 2. Cytogenetic and Molecular Responses of APML patients at Different Stages of Treatment

\begin{tabular}{|c|c|c|c|c|c|c|c|}
\hline \multirow{2}{*}{\multicolumn{2}{|c|}{ Particulars }} & & \multirow[t]{2}{*}{ Number } & \multicolumn{2}{|c|}{$\begin{array}{c}\text { Cytogenetic Response } \\
\text { (Karyotyping) }\end{array}$} & \multicolumn{2}{|c|}{ Molecular Response (q-PCR) } \\
\hline & & & & Remission & Relapse & Remission & Relapse \\
\hline \multirow{2}{*}{\multicolumn{2}{|c|}{ Gender }} & Male & 18 & 16 & 2 & 14 & 4 \\
\hline & & Female & 11 & 9 & 2 & 9 & 2 \\
\hline \multirow{2}{*}{\multicolumn{2}{|c|}{ Age }} & $<30$ & 19 & 15 & 4 & 13 & 6 \\
\hline & & $>30$ & 10 & 10 & 0 & 10 & 0 \\
\hline \multirow{2}{*}{\multicolumn{2}{|c|}{ Dwelling }} & Urban & 7 & 6 & 1 & 5 & 2 \\
\hline & & Rural & 22 & 19 & 3 & 18 & 4 \\
\hline \multirow{10}{*}{ 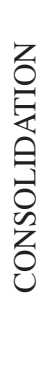 } & & High & 0 & 0 & 0 & 0 & 0 \\
\hline & TLC & Low & 29 & 29 & 0 & 29 & 0 \\
\hline & & \multicolumn{2}{|c|}{$0-20 \%$} & 29 & 0 & 29 & 0 \\
\hline & PML-RAR $\alpha$ q-PCR value (Q-pcr) & \multicolumn{2}{|c|}{$20-40 \%$} & 0 & 0 & 0 & 0 \\
\hline & & \multicolumn{2}{|c|}{$40-60 \%$} & 0 & 0 & 0 & 0 \\
\hline & & \multicolumn{2}{|c|}{ Bcr1 } & 18 & -- & 18 & -- \\
\hline & \multirow[t]{2}{*}{ Transcript type (Qualitative PCR) } & \multirow{2}{*}{\multicolumn{2}{|c|}{$\begin{array}{l}\mathrm{Bcr} 2 \\
\mathrm{Bcr} 3\end{array}$}} & 3 & -- & 3 & -- \\
\hline & & & & 8 & -- & 8 & -- \\
\hline & \multirow{2}{*}{ TLC } & High & 6 & 2 & 4 & 0 & 6 \\
\hline & & Low & 23 & 23 & 0 & 23 & 0 \\
\hline \multirow{6}{*}{ 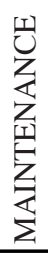 } & \multirow{4}{*}{ PML-RAR $\alpha$ q-PCR value (Q-pcr) } & \multicolumn{2}{|c|}{$0-20 \%$} & 25 & 1 & 23 & 2 \\
\hline & & \multicolumn{2}{|c|}{$20-40 \%$} & 0 & 1 & 0 & 1 \\
\hline & & \multicolumn{2}{|c|}{$40-60 \%$} & 0 & 2 & 0 & 2 \\
\hline & & \multicolumn{2}{|c|}{ Bcr1 } & 17 & 1 & 16 & 2 \\
\hline & \multirow[t]{2}{*}{ Transcript type (Qualitative PCR) } & \multirow{2}{*}{\multicolumn{2}{|c|}{ Bcr2 }} & 2 & 1 & 2 & 1 \\
\hline & & & $\mathrm{Bcr} 3$ & 6 & 2 & 5 & 3 \\
\hline
\end{tabular}

Table 3. Comparative Cytogenetic and Molecular Responses in APML patients

\begin{tabular}{lccccc}
\hline \multicolumn{1}{c}{ Plan } & Response & age $\%$ & Relapse & age $\%$ & 13.8 \\
\hline Cytogenetics & 25 & 86.2 & 04 & 06 & 20.7 \\
Q-pcr & 23 & 79.3 & & 0.7 & \\
Rt-pcr Qualitative & & & 02 & 11.1 \\
bcr-1 & 16 & 55.1 & 01 & 33.4 \\
bcr-2 & 02 & 6.9 & 03 & 37.5 \\
bcr-3 & 05 & 17.2 & & 0.2 \\
\hline
\end{tabular}

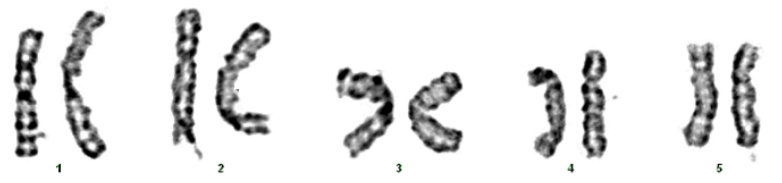

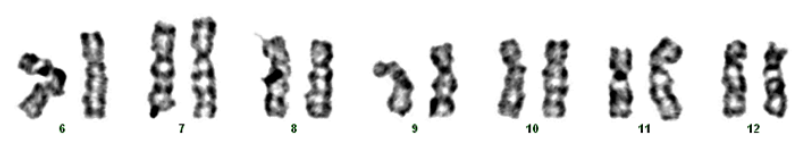

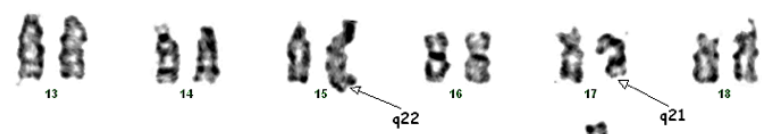
$b_{10} \quad \sum_{20} \mathrm{R}$ Q.4. 84

Figure 1. Representative Karyotype of the $t(15 ; 17)$ complement from PHA induced peripheral blood culture

30 patients $(81 \%)$ with promyelocyte count greater than $60 \%$ (Table 1).

Initial PHA-stimulated peripheral blood karyotyping revealed 30 patients $(81 \%)$ positive for $\mathrm{t}(15 ; 17)$ whereas 7 patients $(19 \%)$ had either cryptic translocation or were negative for $\mathrm{t}(15 ; 17)$ (Figure 1). Incidentally, 02 such cases were detected as variants with chromosome 16q deletion and no hallmark translocation $\mathrm{t}(15 ; 17)$ (Figure

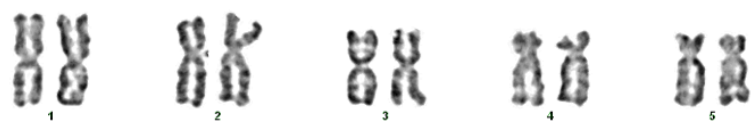

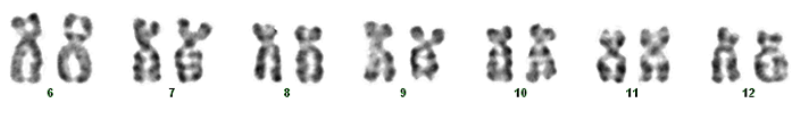

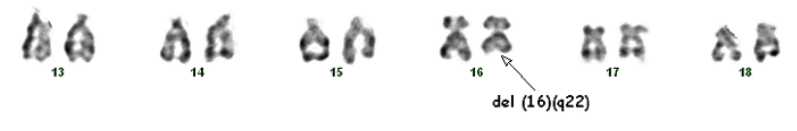

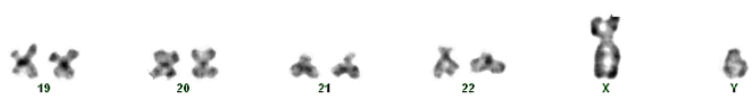

Figure 2. Representative Karyotype showing chromosome 16q deletion in APML patient

2). The PHA-unstimulated cultures were not as reliable as the PHA-stimulated ones and were unable to report the variant karyotypes, which were clearly detected by the PHA-stimulated ones (Figure 3). The Q-PCR status for PML-RAR $\alpha$ was found to be $\leq 60 \%$ for 21 patients $(56.7 \%)$ while as it was $>60 \%$ for 13 patients $(35.1 \%)$ (Table 1). 3 patients had bcr-2 transcripts as detected by qualitative RT-PCR and could not be quantified because 


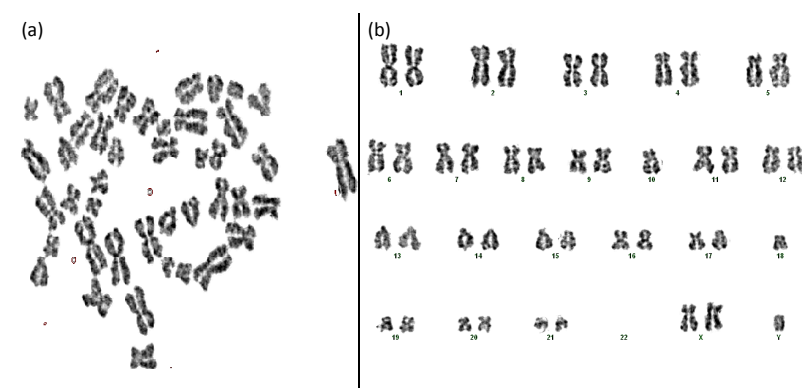

Figure 3. Representative metaphase (A) and its Karyotype (B) from unstimulated peripheral blood sample of APML patient

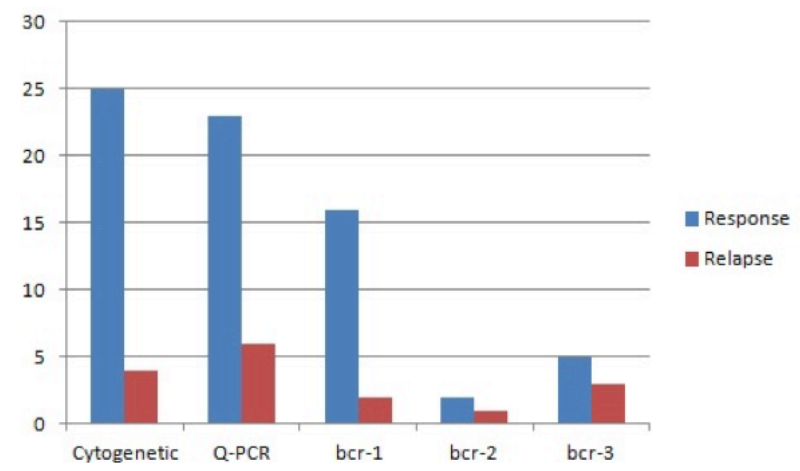

Figure 4. Prognostic significance of Cytogenetic, Molecular (Q-PCR) and Transcript types (RT-PCR) in APML patients

most of the kits available quantify only bcr-1 and bcr-3 fusion transcripts.

Of the 37 patients at presentation, 22 patients $(59.4 \%)$ had bcr- 1,03 patients $(8.1 \%)$ bcr- 2 and 12 patients $(32.4 \%)$ were observed to harbor bcr-3 transcript (Table 1).

27 patients $(72.9 \%)$ were subjected to treatment with ATRA based protocols whereas remaining 10 (27.1\%), which included 6 relapsed and 4 newly diagnosed patients, were treated with arsenic tri -oxide $\left(\mathrm{AS}_{2} \mathrm{O}_{3}\right)$ based protocols exclusively. During the course of study 08 patients $(21.6 \%)$ expired including 05 males $(13.5 \%)$ and 03 females $(8.1 \%)$. Among these 06 patients died during induction phase of the treatment while as 02 patients relapsed and expired at the maintenance stage of chemotherapy (Table 1).

We followed 29 patients treated with either ATRA (in addition to conventional chemothera-py) (ICAPL-2006) or with $\mathrm{AS}_{2} \mathrm{O}_{3}$. All patients achieved hematological remission (Differenti-ation) within first 35 days whereas molecular remission was achieved at different stages of consolidation phase of chemotherapy as revealed by normal TLC and platelet counts, negative Q-PCR, RT-PCR status for PML-RAR $\alpha$ fusion gene and also the absence of $\mathrm{t}(15 ; 17)$ cytogenetically (Table 2 ).

Of the 29 patients, 06 patients presented with high TLC, 4 of them during maintenance and 2 after completion of maintenance phase of chemotherapy. All 6 patients had molecular relapse as indicated by their RT-PCR and Q-PCR values for PML-RAR $\alpha$ fusion gene which was less than $20 \%$ for 2 patients, 20 to $40 \%$ for one patient and 40 to $60 \%$ for other two patients. 1 patient being bcr-
DOI:http://dx.doi.org/10.7314/APJCP.2016.17.4.1999 PHA Stimulated Peripheral Blood Cytogenetics in APML Cases 2 positive could not be quantified. 02 of the 06 patients with molecular relapse had bcr-1 fusion transcript, one patient had bcr-2 fusion transcript, whereas bcr-3 transcript was detected in 03 patients. The molecular follow-up corresponded/concorded completely with the PHA-stimulated peripheral blood cultures and not with PHA-unstimulated ones, where 4 of the 6 relapsed patients had cytogenetic relapse in addition to molecular relapse (Table 2) (Figure 4).

\section{Discussion}

The $\mathrm{t}(15 ; 17)$ is the diagnostic hallmark of APML and initially had been considered to be pre-sent in all patients with this condition (Warrell et al., 1993). However, it is now clear from that a sizeable minority of APML patients actually lack this chromosomal aberration (David Grimwade et al., 2000). Three diagnostic approaches namely cytogenetics, quantita-tive reverse transcriptasepolymerase chain reaction (Q-PCR) and FISH analysis efficiently help in the diagnosis, management and treatment of APML. In APML a specific disease marker, i.e, the PCR amplifiable PML/RAR $\alpha$ fusion gene, allows molecular assessment of response to treatment and minimal residual disease (MRD) evaluation in $100 \%$ of patients (Cassnat B, et al., 2000). Cytogenetics detects the $\mathrm{t}(15 ; 17)$ in the majority of patients, identi-fies secondary cytogenetic changes, and has revealed novel translocations in APML, prompting subsequent molecular characterization of their respective breakpoint regions. Thus, evalua-tion of $\mathrm{t}(15 ; 17)$ in APML by conventional karyotyping is still considered as a standard tool for base line detection and for monitoring the targeted therapy.

Although the conventional cytogenetic studies on bone marrow have been viewed as the standard diagnostic and follow-up method for patients on chemotherapy, the technique con-tinues to be confronted with the issue of quality of the signal metaphases produced, which are compact and dysmorphic, thereby making them not amenable to prominent G-banding for easy and convenient analysis (Seabrigth, 1971; Bennett et al., 1985). In a previous study conducted on patients with chronic myeloid leukemia, use of PHA and that too on the peripheral blood showed good promise of serving as a reliable alternative to the conventional PHA-free cytogenetics as there was a marked improvement in terms of the quality of the metaphases generated with PHA-induced cultures of peripheral blood (Niyaz A Azad, et al., 2015). In line with this assessment, we aimed to evaluate the application of Phytohemagglu-tinin (PHA)-induced peripheral blood culture based cytogenetic analysis (Karyotyping) in base line diagnosis and monitoring chemotherapy response of the APML patients of Kashmir region (North India). Patients were also assessed by Q-PCR and RT-PCR at base line and fol-low up to correlate with cytogenetic evaluation. In this study we replicated the same procedure but the samples were peripheral blood from APML patients

In our cytogenetic report, additional chromosomal alterations were observed in $19 \%$ of the APML patients in tandem with the marker translocation $t(15 ; 17)$. The 
additional chromoso-mal abnormalities found in our study included chromosome 16 (q) deletion, 16q del with loss of Y chromosome, more complex karyotypes were found in $17.1 \%$ of the APML patients. It is well documented that the incidence of chromosome abnormalities in addition to $\mathrm{t}(15 ; 17)$ in APML has been reported before to be around $25-40 \%$ in primary APML patients and even higher in relapse (De Botton et al., 2000). 66\% of (4 of 6) the APML patients with relapse had complex karyotype with presence of some unidentified marker signatures in addition to marker translocation $\mathrm{t}(15 ; 17)$. Several studies have reported a series of alternative chromo-somal aberrations including $\mathrm{t}(11 ; 17)$ (Chen et al., 1993; Chen et al., 1993; Wells et al., 1997), t(5;17) (Redner et al., 1996), and $\operatorname{del}(17)$ (Arnould et al., 1999) whereby RAR $\alpha$ is fused to the PLZF, NPM, NuMA, and STAT5b genes, respectively. However, we did not find any such translocations in our series of APML cases.

In addition to the diagnostic work-up of APML by conventional or fluorescent in situ hybrid-ization (FISH) cytogenetic (Iqbal S, et al., 2000), molecular detection of PML-RARA fusion gene by quantitative RT-PCR helps in base line detection and monitoring minimal residual disease (Wang AM, et al.,1989 ; Cassnat B, et al., 2000). We used Q-PCR assay for detection of the PML/RAR-a rearrangement with high sensitivity. The assay was performed on APML cells obtained from 37 patients whose APML diagnosis was made by conventional clinical cri-teria as well as peripheral blood cytogenetics. The results reveal that this Q-PCR assay for the PML/RAR $\alpha$ fusion mRNA is more sensitive. By Q-PCR for PMLRAR $\alpha$, we found all the patients positive for PML-RAR $\alpha$ except 03 patients whose minimal residual disease (MRD) could not be ascertained as they were found to harbor bcr-2 transcripts by RT-PCR. This is because most of the kits available quantify only bcr- 1 and bcr- 3 fusion transcripts . The per-formance of this assay was observed to be reliable in diagnosis and later follow up the APML patients.

Of the total 37 patients enrolled initially in this study, 08 patients expired during the course of study, out of which 06 patients died during induction phase of the treatment and 02 patients relapsed and expired at the maintenance stage of chemotherapy. Out of the remaining 29 patients, 19 were treated with ATRA based protocols and 10 patients (6 relapsed and 4 newly diagnosed patients) were treated with arsenic tri-oxide $\left(\mathrm{AS}_{2} \mathrm{O}_{3}\right)$ based protocols (Shen et al., 1997; Ghavamzadeh et al., 2006; 2010). There was $100 \%$ remission at both cytogenetic and molecular level in consolidation phase confirming ATRA based protocols as effective means to produce complete remission and long-term cures, although in some cases, remissions do not appear to be long term which was evident in our study as well as the stud-ies conducted earlier (Huang et al., 1988; Castaigne et al., 1990; Chomienne C, et al., 1990; Warrell et al., 1991). All the APML patients were reassessed during maintenance phase where 6 patients showed relapse as evident by positive RT-PCR in all the 6 patients and 4 showed cytogenetic relapse as well. All the 6 relapsed patients were treated with Arse-nic tri-oxide $\left(\mathrm{AS}_{2} \mathrm{O}_{3}\right.$ ) exclusively (Shen et al., 1997). Two patients died during this phase which had a complex Karyotype with
$6 \mathrm{q}$ deletion in addition to marker transloca-tion $\mathrm{t}(15 ; 17)$. In our study molecular analysis (Q-PCR + RT-PCR) was found more sensitive while following the disease status of the patients as it picked up six patients as compared to 4 by cytogenetics which were later found to have the relapse upon clinical correlation.

We evaluated the transcripts types of all the 37 APML patients by qualitative RT-PCR, where bcr-1 frequency was found to be highest in $22(59.4 \%)$ followed by bcr-3 transcript in 12 pa-tients $(32.4 \%)$ and 03 patients were bcr-2. It is known that breakpoint on chromosome 17 in-variably disrupts the RARA gene in the second intron, but rearrangement of the PML gene may occur at 2 major breakpoints, one within PML intron 3 (bcr-3) yielding the short fusion mRNA transcript that joins PML exon 3 and RAR-a exon 3. Another breakpoint occurs with-in PML intron 6 (bcr-1) that consistently produce the long transcript from the joining of PML exon 6 to RAR-a exon 3. Additionally, breakpoints within PML exon 6 (bcr-2) are associated with a variable length transcript in a small number of patients (Miller WH Jr, et al., 1992; Borrow J, et al., 1992; Pandolfi PP, et al., 1992; Biondi A, et al., 1992). The influence of breakpoint site on patient outcome remains controversial. Early reports suggested that patients who express the short isoform have an increased incidence of clinical relapse and shorter survival compared to patients with the long isoform (Huang et al., 1993; Vahdat et al., 1994). Others have reported no difference in disease-free survival between patients with the long or short isoforms after adjusting for the association of the short form with a higher leukocyte count at presentation (Gallagher et al., 1997). Our study found that $37.5 \%$ APML patients showed relapse with a short transcript type (BCR 3) and had unfavor-able prognosis as compared to patients with a long transcript type (BCR1-2) who had relapse in only $11 \%$ patients (Table 3 ). Similar scenario was depicted by Huang et al. (1993) who have reported that patients with a BCR 3 treated with ATRA alone have a more unfavorable prognostic outcome than patients with bcr 1-2. One more study conducted by Vahdat.et.al has depicted the similar picture regarding the prognosis of the APML patients on the basis of presence of the transcripts (Vahdat et al., 1994).

Further investigations in larger series are needed in order to establish whether different PML breakpoints are associated with variable diagnostic features and/or prognosis. Finally, the clinical significance of additional karyotypic abnormalities sometimes found in APML has not been evaluated.

\section{Acknowledgement}

We appreciate the cooperation of the patients of this study as also the resident staff of the Departments of Medical Oncology and Clinical Hematology of SKIMS for their help and support. We are thankful to the SKIMS administration for funding this study.

\section{References}

Ghavamzadeh A, Alimoghaddam K, Ghaffari SH, et al (2006). 
Treatment of acute pro myelocytic leukemia with arsenic trioxide without ATRA and/or chemotherapy. Annals Oncol, 17, 131-4.

Arnould C, Philippe C, Bourdon V, et al (1999). The signal transducer and activator of trans cription STAT5b gene is a new partner of retinoic acid receptor a in acute promyelocyti

clike leukemia. Hum Mol Genet, 8, 1741-9.

Arshad A. Pandith, Mushtaq A. Siddiqi (2012). Burden of cancers in the valley of Kashmir 5 year epidemiological reveals a different scenario. Tumor Biol, 33, 1629-37.

Bennett JM, Catovsky D, Daniel MT, et al (1985). Proposed revised criteria for the classifi cation of acute myeloid leukemia: a report of the French-American-British Cooperative Group. Ann Intern Med, 103, 460-2.

Biondi A, Rambaldi A, Pandofi PP, et al (1992). Molecular monitoring of myl/RAR-a fusion gene in acute promyelocytic leukemia by polymerase chain reaction. Blood, 80, 492-7.

Borrow J, Goddard AD, Gibbons B, et al (1992). Diagnosis of acute promyelocytic leukae mia by RT- PCR detection of PML-RARA and RAR-PML fusion transcripts. $\mathrm{Br} J$ Haematol, 82, 529-40.

Carbone R, Botrugno OA, Ronzoni S, et al (2006). Recruitment of the histone methyltransfe rase SUV39H1 and its role in the oncogenic properties of the leukemia-associated PML retinoic acid receptor fusion protein. Mol Cell Biol, 26,1288-96.

Cassnat B, Zassadowski F, Balitrand N, et al (2000). Quantitation of minimal residual disease in acute promyelocytic leukemia patients with $\mathrm{t}(15 ; 17)$ translocation using real-time RT- PCR. Leukemia, 14, 324-8

Castaigne S, Chomienne C, Daniel MT, et al (1990). Alltrans retinoic acid as a differentia tion therapy for acute promyelocytic leukemia. I. Clinical results. Blood, $\mathbf{7 6}$, 1704-9.

Chen SJ, Zelent A, Tong JH, et al (1993). Rearrangements of the retinoic acid receptor alpha and promyelocytic zinc finger genes resulting from $\mathrm{t}(11 ; 17)(\mathrm{q} 23 ; \mathrm{q} 21)$ in a patient with acute promyelocytic leukaemia. J Clin Invest, 91, 2260-7.

Chen Z, Brand NJ, Chen A, et al (1993). Fusion between a novel Kruppel-like zinc finger gene and the retinoic acid receptor-a locus due to a variant $\mathrm{t}(11 ; 17)$ translocation asso-ciated with acute promyelocytic leukaemia. EMBO J, 12, 1161-7.

Chomienne C, Ballerini P, Balitrand N et al (1990). All-trans retinoic acid in acute promye locytic leukemias. In vitro studies Structure-function relationship. Blood, 76, 1710-7.

David Grimwade, Andrea Biondi, Marie-Joëlle Mozziconacci, et al (2000). Characterization of acute promyelocytic leukemia cases lacking the classic $t(15 ; 17)$ : results of the euro-pean working party. groupe français de cytogénétique hématologique, groupe de français d'hematologie cellulaire, UK cancer cytogenetics group and BIOMED 1 Eu-ropean community-concerted action "molecular cytogenetic diagnosis in haematolo-gical malignancies. Blood, 96, 1297-308.

De Botton S, Chevret S, Sanz M, et al (2000). Additional chromosomal abnormalities in pa-tients with acute promyelocytic leukaemia (APML) do not confer poor prognosis results of APML 93 trial. Br J Haematol, 111, 801-6.

Di Croce L, Raker VA, Corsaro M, et al (2002). Methyltransferase recruitment and DNA Hypermethylation of target promoters by an oncogenic transcription factor. Science, 295, 1079-82.

Dilworth FJ, Chambon P (2000). Nuclear receptors coordinate the activities of chromatin re-modeling complexes and coactivators to facilitate initiation of transcription. Oncogene, 20, 3047-54.

Douer D, Santillana S, Ramezani L, et al (2003). Acute
DOI:http://dx.doi.org/10.7314/APJCP.2016.17.4.1999

PHA Stimulated Peripheral Blood Cytogenetics in APML Cases promyelocytic leukaemia in patients originating in Latin America is associated with an increased frequency of the bcrl sub-type of the PML/RARalpha fusion gene. $\mathrm{Br} J$ Haematol, 122, 563-70.

Gallagher R, Willman CL, Slack JL, et al (1997). Association of PML/RARa fusion mRNA type with pretreatment hematologic characteristics but not treatment outcome in acute promyelocytic leukemia: an intergroup molecular study. Blood, 90, 1656-63.

Ghavamzadeh A, Alimoghaddam K, Rostami S, et al (2011). Phase II study of single- agent arsenic trioxide for the front-line therapy of acute promyelocytic leukemia. J Clin Oncol, 29, 2753-7.

Glass CK, Rosenfeld MG (2000). The coregulator exchange in transcriptional functions of nuclear receptors. Genes Dev, 14, 121-41.

Grimwade D (1999). The pathogenesis of Acute Promyelocytic Leukemia; Evaluation of the role of molecular diagnosis and monitoring in the management of the disease. $\mathrm{Br} \mathrm{J} \mathrm{Hema-}$ tol, 106, 591-613.

Huang M, Ye YC, Chen BR, et al (1988). Use of all-trans retinoic acid in the treatment of acute promyelocytic leukemia. Blood, 72, 567-72.

Huang W, Sun GL, Li ZS, et al (1993). Acute promyelocytic leukemia: clinical relevance of two major PML-RARa isoforms and detection of minimal residual disease by retrotrans-criptase/polymerase chain reaction to predict relapse. Blood, 82, 1264-9.

Iqbal S, Grimwade D, Chase A, et al (2000). Identification of PML/ RARalpha rearrange ments in suspected acute promyelocytic leukemia using fluorescence in situ hybridization of bone marrow smears: a comparison with cytogenetic and RT-PCR in MRC ATRA trial patients. MRC Adult Leukaemia Working Party. Leukemia, 14, 950-3.

Jensen K, Shiels C, Freemont PS (2001). PML protein isoforms and the RBCC/TRIM motif. Oncogene, 20, 7223-33.

Miller WH Jr, Kakizuka A, Frankel SR, et al (1992). Reverse transcription polymerase chain reaction for the rearranged retinoic acid receptor-a clarifies diagnosis and detects minimal residual disease in acute promyelocytic leukemia. Proc Natl Acad Sci USA, 89, 2694-8.

Mitelman F (1995). An International System for Human Cytogenetic Nomenclature. S Karger.

Niyaz A Azad, Shahid M Baba, Zafar A Shah, et al (2015). Phytohemagglutinin-induced pe-ripheral blood cytogenetics: a valid means for diagnosis and imatinib therapy monitoring of chronic phase chronic myeloid leukemia patients. $J$ Cancer Sci Ther, 7, 242-248.

Pandolfi PP (2001). In vivo analysis of the molecular genetics of acute promyelocytic leu-kemia. Oncogen, 20, 5726-35.

Pandolfi PP, Alcalay M, Fagioli M, et al (1992). Genomic variability and alternative splicing generate multiple PML/ RARa transcripts that encode aberrant PML proteins and PML/RARa isoforms in acute promyelocytic leukemia. EMBO J, 11, 1397-407.

Redner RL, Rush EA, Faas S, et al (1996). The t $(5 ; 17)$ variant of acute promyelocytic leu-kemia expresses a nucleophosminretinoic acid receptor fusion. Blood, 87, 882-886.

Seabrigth M (1971). A rapid banding technique for human chromosomes. Lancet, 2, 971-72.

Shen Z-X, Chen G-Q, Ni J-H, et al (1997). Use of arsenic trioxide $\left(\mathrm{AS}_{2} \mathrm{O}_{3}\right)$ in the treatment of acute promyelocytic leukemia (APML): II. Clinical efficacy and pharmacokinetics in relapsed patients. Blood, 89, 3354-60.

So CC, Wan TS, Chow JL, et al (2011). A single-center cytogenetic study of 629 Chinese patients with de novo acute myeloid leukemia evidence of major ethnic differences and a 
high prevalence of acute promyelocytic leukemia in Chinese patients. Cancer Genet, 204, 430-8.

van Dongen JJ, Macintyre EA, Gabert JA, et al (1999). Standardized RT-PCR analysis of fusion gene transcripts from chromosome aberrations in acute leukemia for detection of mi-nimal residual disease. Report of the BIOMED-1 Concerted Action investigation of mini-mal residual disease in acute leukemia. Leukemia, 13, 1901-28.

Vahdat L, Maslak P, Miller WH Jr, et al (1994). Early mortality and retinoic acid syndrome in acute promyelocytic leukemia: impact of leukocytosis, lowdose chemotherapy, PML/RAR-a isoform, and CD13 expression in patients treated with alltrans retinoid acid. Blood, 84, 3843-9.

Villa R, Morey L, Raker VA, et al (2006). The methyl-CpG binding protein MBD1 is requi-red for PML- RARalpha function. Proc Natl Acad Sci U S A, 103, 1400-5.

Wang AM, Doyle MV, Mont DF (1989). Quantification of mRNA by polymerase chain reac-tion. Proc Natl Acad Sci USA, 86, 9717-21.

Warrell RP, Frankel SP, Miller WH, et al (1991). Differentiation therapy of acute promyelo-cytic leukemia with tretinoin (allt"-retinoic acid). $N$ Engl J Med, 324,1385-9.

Warrell R.P. Jr, de The H, Wang ZY, et al (1993). Acute Promyelocytic leukemia. N Eng J Med, 329, 177-89.

Wells RA, Catzavelos C, Kamel-Reid S (1997). Fusion of retinoic acid receptor a to NuMA, the nuclear mitotic apparatus protein, by a variant translocation in acute promyelocytic leukaemia. Nat Genet, 17,109-113.

Zhong S, Salomoni P, Pandolfi PP (2000). The transcriptional role of PML and the nuclear body. Nat Cell Biol, 2, 85-90. 